\title{
Hubungan Harga Diri dan Fear of Missing Out dengan Smartphone Addiction Mahasiswa Universitas Negeri Semarang
}

\author{
Ikhfatul Aulyah', Binti Isrofin ${ }^{2}$ \\ 1,2 Jurusan Bimbingan dan Konseling, Universitas Negeri Semarang (UNNES) \\ e-mail: ikhfatulaulyah@students.unnes.ac.id
}

\begin{abstract}
ABSTRAK. Penelitian ini dilatarbelakangi dengan banyaknya fenomena kecanduan smartphone pada remaja yang dapat mempengaruhi tugas perkembangan di fase emerging adulthood. Tujuan dari penelitian ini adalah untuk mengetahui hubungan harga diri dan fear of missing out dengan smartphone addiction melalui pendekatan korelasional dengan model ex post facto. Sampel penelitian sebanyak 344 yang dipilih melalui teknik proportional random sampling. Data diungkap dengan skala psikologis smartphone addiction scale short version (SAS-SV) dari Kwon, skala harga diri yang diadaptasi dari Coopersmith dan Fear of Missing Out Scale (FoMOS) dari Przyblylski. Hasil penelitian menunjukan bahwa harga diri dan fear of missing out merupakan faktor yang dapat memprediksi smartphone addiction sebesar 17\% dan 83\% ditentukan oleh faktor lain yang tidak diteliti
\end{abstract}

Kata kunci: Smartphone Addiction, Harga Diri, Fear of Missing Out

\section{Pendahuluan}

Perkembangan teknologi di era revolusi industri 4.0 membawa berbagai pengaruh dalam hampir semua sisi kehidupan manusia. Salah satu pengaruh dari perkembangan teknologi tersebut adalah munculnya teknologi telepon pintar atau smartphone. Penciptaan dan perkembangan smartphone telah mengubah kehidupan manusia. Smartphone telah menjadi bagian dari kehidupan manusia, bahkan orang-orang merasa tidak bisa dipisahkan dari smartphone mereka (Lepp, 2015).

Pengguna smartphone pada tahun 2013 mencapai 1,9 miliar, merepresentasikan 27\% populasi dunia dan diprediksi jumlah pengguna smartphone akan terus meningkat sampai 5,6 miliar pada tahun 2019 (Ericsson Mobility, 2013). Data dari Pew Research Center (Smith, 2015) menunjukkan bahwa 46\% dari pengguna smartphone di Amerika Serikat mengaku bahwa mereka “Tidak bisa hidup tanpa smartphone”. Disamping itu, dalam tiga tahun dari tahun 2011-2014, persentase kepemilikan smartphone di kalangan orang dewasa di Amerika Serikat meningkat pesat dari 35\% menjadi 64\% (Smith, 2015). Selanjutnya, 15\% dari populasi warga Amerika Serikat berumur 18 dan 29 tahun terindikasi ketergantungan pada smartphone guna mengakses internet (Smith, 2015).

Di Indonesia, terdapat 371,4 juta atau setara dengan $142 \%$ jumlah penduduk menggunakan ponsel (We Are Social, 2017). Sedangkan Emarketer (2014) menyebutkan bahwa Indonesia berada di tingkat ke-7 dengan negara pengguna ponsel terbanyak. Bahkan sebuah studi yang dilakukan oleh MillwardBrown (2014) Indonesia menjadi negara dengan peringkat kecanduan 
tertinggi di dunia dengan penggunaan smartphone rata-rata 3 jam per hari. Tercatat $61 \%$ warga di Bandung, Bodetabek, Jakarta, Semarang dan Surabaya memiliki ponsel pintar. Rata-rata pemakaian ponsel pintar pada beberapa kota tersebut yaitu selama 5,5 jam per hari dan biasanya terjadi pada malam hari (Batamnews. 2015).

Banyaknya pengguna smartphone dapat mendorong meningkatnya penggunaan smartphone dalam kehidupan sehari-hari yang mana hal ini dapat berdampak positif dan negatif. Beberapa dampak positif penggunaan smartphone yang dilansir oleh addictiontips.com (2019) yaitu smartphone dapat mempermudah komunikasi, sebagai media hiburan, meningkatkan pengetahuan meningkatkan kenyamanan dalam belajar, meningkatkan kemampuan untuk mengatur waktu, meningkatkan kemampuan mengingat, tersedianya teknologi canggih. Selain itu menurut Matlubah dkk (2016) smartphone juga dapat meningkatkan motivasi belajar mahasiswa. Penggunaan smartphone memang banyak memberikan manfaat dan dampak positif bagi kehidupan saat ini, tetapi smartphone juga memiliki beberapa dampak negatif. Menurut Singh dan Samah (2018), smartphone dapat membuat tidak fokus pada saat belajar, mengakibatkan kecanduan, kurangnya interaksi sosial di kehidupan nyata, prestasi akademik menurun, kurangnya empati pada lingkungan sekitar, meningkatkan level kecemasan dan depresi, mengganggu waktu tidur sehingga dapat mengganggu kesehatan, mengurangi daya tangkap dan daya ingat dan mempermudah dalam tindakan kecurangan. Selain itu, Taneja (2014) menyebutkan bahwa smartphone dapat mengakibatkan kecemasan, insomnia, kecanduan smartphone atau nomophobia, bahkan menyebabkan delusi.

Menurut Kwon, dkk (2013) istilah kecanduan smartphone atau smartphone addiction adalah sebagai perilaku keterikatan atau ketergantungan terhadap smartphone yang memungkinkan menjadi masalah sosial seperti halnya menarik diri, dan kesulitan dalam performa aktivitas sehari-hari atau sebagai gangguan kontrol impuls tehadap diri seseorang. Menurut Lin, dkk (2014), kecanduan smartphone dapat dianggap sebagai salah satu bentuk kecanduan teknologi. Griffith dalam Lin, dkk (2014) mendefinisikan secara operasional bahwa kecanduan teknologi sebagai kecanduan perilaku yang melibatkan interaksi manusia mesin dan non kimia di alam, pola perilaku serupa, kecanduan pada internet telah dikategorikan sebagai tipe yang substans terkait dan gangguan adiktif dalam DSM-V.

Smartphone menjadi kebutuhan mendasar pada semua kalangan usia di seluruh dunia saat ini (Samaha dan Hawi, 2016). Dilansir oleh Tempo.Co (2019) bahwa pengguna smartphone kebanyakan adalah pemakai muda dengan rentang usia 18-34 tahun mencapai 66\%. Rentang usia ini dapat digolongkan sebagai remaja akhir dan dewasa awal, yaitu usia 18-21 tahun dan 22-24 tahun (Monks, Knoers, Haditono, 2006). Daya tarik smartphone membuat remaja rentan terpengaruh (Nakaya, 2014). Hasil riset tersebut didukung Ho, Lwin, dan Lee (2017) yang mendata berdasarkan survei di Singapura bahwa remaja adalah populasi yang paling banyak terdeteksi menggunakan media sosial di smartphone secara berlebihan, atau bahkan sampai berujung pada adiksi.

Jhon W. Santrock (2011) masa remaja (adolescence) adalah periode perkembangan transisi dari masa kanak-kanak hingga masa dewasa yang mencakup perubahan-perubahan biologis, kognitif, dan sosial emosional. Santrock juga menjelaskan bahwa rentang usia remaja dimulai pada usia 10-12 tahun, dan berakhir pada usia 21-22 tahun. Sedangkan menurut Arnett dalam Santrock (2011) rentang usia 18-25 tahun dijelaskan sebagai periode transisi dari masa 
remaja ke dewasa atau beranjak dewasa (emerging adulthood) dengan lima ciri perkembangan yaitu, eksplorasi identitas, ketidakstabilan, self-focused, feeling in-between dan usia dengan berbagai kemungkinan. Pada tingkat perkembangan ini umumnya berada pada tingkat pendidikan perguruan tinggi atau sebagai mahasiswa.

Berdasarkan kondisi tugas perkembangan emerging adulthood ini individu berupaya untuk memenuhi tugas perkembangan tersebut dengan mencari pengalaman-pengalaman baru. Pengalaman-pengalaman itu mengakibatkan berbagai macam emosi dari mulai perasaan bebas dan optimis hingga rasa takut untuk mengeksplorasi diri sehingga membawa mereka kearah yang ketidakjelasan (Arnet, 2004). Kondisi-kondisi inilah yang membuat individu pada masa remaja rentan mengalami kecanduan (Lee dan Lee, 2017). Menururt Agusta (2016) secara deskriptif faktor-faktor penyebab remaja kecanduan smartphone, yaitu: sensation seeking saat menggunakan smartphone yang tinggi, self-esteem dan self-control yang rendah, situasi psikologis, pemasaran produk smartphone dan kebutuhan dalam interaksi sosial. Sementara itu menurut Walsh et al (2007) menyebutkan bahwa faktor penyebab dari kecanduan smartphone adalah self gratification, yaitu smartphone sebagai sarana menghibur diri dan social gratification yaitu smartphone digunakan untuk terus terhubung dengan orang lain. Dengan demikian diketahui bahwa self esteem yang rendah dan FoMO (Fear of Missing Out) merupakan faktor yang menyebabkan smartphone addiction.

Self-esteem atau Harga diri menurut Coopersmith (1967) adalah suatu penilaian yang dilakukan oleh individu terhadap dirinya sendiri. Individu yang harga dirinya tinggi akan menghormati dirinya sendiri, menganggap bahwa dirinya berharga dan melihat bahwa dirinya sama seperti orang lain. Harga diri dalam diri seseorang dapat mempengaruhi tingkat kecanduan seseorang dalam menggunakan smartphone. Menurut Sing et al (2014) orang yang memiliki tingkat harga diri yang rendah akan mengalami smartphone addiction. Orang yang memiliki harga diri rendah biasanya lebih banyak membutuhkan dukungan dari teman atau lingkungan sekitar sebagai upaya agar mereka merasa lebih dihargai (Kurcaburun, 2016). Hal ini dijelaskan juga oleh Bianchi dan Philips (2005) bahwa penggunaan smartphone dipengaruhi oleh harga diri. Individu yang memiliki harga diri rendah akan lebih memilih berkomunikasi secara tidak langsung melalui media sosial sementara individu dengan harga diri yang tinggi lebih menyukai komunikasi secara face to face (komunikasi langsung).

Selain harga diri atau self esteem, dalam perkembangan klasifikasi gangguan penggunaan smartphone timbul gejala baru yang dinamakan fear of missing out (FoMO). Menurut Przyblylski, Murayama, DeHaan dan Gladwell (2013) FoMO ( fear of missing out) merupakan ketakutan akan kehilangan momen berharga individu atau kelompok lain di mana individu tersebut tidak dapat hadir didalamnya dan ditandai dengan keinginan untuk tetap terus terhubung dengan apa yang orang lain lakukan melalui internet atau dunia maya. Orang-orang dengan kepuasan kebutuhan dasar rendah umumnya mempersepsikan media sosial sebagai platform untuk terhubung dengan orang lain agar dapat mengembangkan kompetensi sosial mereka dan menjadi kesempatan untuk memperdalam ikatan sosial (Przybylski et al.,2013). Mengingat bahwa terlibat dalam jejaring sosial adalah kegiatan utama dalam menggunakan teknologi seluler, maka Fear of missing out (FoMO) terkait dengan penggunaan smartphone. Penelitian yang dilakukan oleh Tuch-Aksan (2019) yang menunjukkan fear of missing out (FoMO) pada remaja mempengaruhi penggunaan bermasalah terhadap media sosial, dimana hal ini dapat menyebabkan smartphone addiction. 
Implikasi penelitian ini di bidang bimbingan konseling yaitu untuk memenuhi fungsi layanan bimbingan dan konseling yaitu fungsi pencegahan dan fungsi penyesuaian. Fungsi pencegahan yaitu mencegah konseli terlibat dalam masalah yang dapat mengganggu tugas perkembangan individu dengan cara memberikan informasi mengenai harga diri, FoMO dan smartphone addiction. Fungsi penyesuaian membantu individu dalam menyesuaikan diri dengan lingkungannya. Lingkungan yang semakin berkembang dan dekat dengan teknologi terutama smartphone membuat individu memiliki resiko kecanduan smartphone.

Berdasarkan penjelasan diatas penelitian ini bertujuan untuk mengetahui hubungan antara harga diri, FoMO dan smartphone addiction serta mengetahui bagaimana pengaruh antara variable independen dengan dependennya.

\section{Metode}

Metode penelitian ini menggunakan menggunakan jenis penelitian expost facto dengan pendekatan korelasional. Pada penelitian expost facto, menurut Widarto (2013) secara metodologis merupakan penelitian eksperimen yang menguji hipotesis tetapi tidak memberikan perlakuan atau memberikan manipulasi. Sedangkan Arikunto (2009:247) menjelaskan bahwa penelitian korelasional merupakan penelitian yang dimaksudkan untuk mengetahui ada tidaknya hubungan antara dua atau beberapa variabel. Penelitian ini menggunakan teknik sampling Proportional Random Sampling dengan pengambilan sampel berdasarkan pada tabel Isaac dan Michael dengan taraf kesalahan 5\% dari jumlah populasi mahasiswa Universitas Negeri Semarang yang berjumlah 29.007. Sehingga dihasilkan jumlah sampel sebanyak 344 mahasiswa yang diambil dari semua jurusan dan angkatan. Teknik pengumpulan data yang digunakan adalah skala psikologis smartphone addiction scale short version (SAS-SV) dari Kwon yang terdiri dari 10 item, skala psikologis harga diri yang terdiri dari 45 item dan fear of missing out scale (FoMOS) dari Przybylski yang terdiri dari 10 item. Ketiga skala psikologis sudah diuji oleh ahli (expert judgment) dan melalui hasil uji validitas dan reliabilitas. Jenis skala yang digunakan dalam penelitian ini adalah skala likert. Analisis data yang digunakan dalam penelitian ini menggunakan analisis product momen dan regresi ganda dengan menggunakan bantuan aplikasi JASP.

\section{Hasil}

Mengacu pada tabel 1 di bawah ini mengenai data tingkat smartphone addiction, maka diketahui bahwa mahasiswa Universitas Negeri Semarang memiliki tingkat kecanduan smartphone dengan persentase paling banyak ada pada kategori sedang yaitu sebesar 42,4\%.

Tabel 1. Data Tingkat Kecanduan Smartphone

\begin{tabular}{ccccc}
\hline No. & Kelas Interval & Frekuensi & Percent & Kategori \\
\hline 1. & $10-17,4$ & 16 & 4,7 & Sangat Rendah \\
2. & $17,5-22,4$ & 97 & 28.2 & Rendah \\
3. & $22,5-27,4$ & 146 & 42.4 & Sedang \\
4. & $27,5-32,4$ & 60 & 17.4 & Tinggi \\
5. & $32,5-40$ & 25 & 7.3 & Sangat Tinggi \\
& Total & $\mathbf{3 4 4}$ & $\mathbf{1 0 0}$ & \\
\hline
\end{tabular}


Semantara itu pada tabel 2 didapatkan data tingkat harga diri mahasiswa Universitas Negeri Semarang memiliki frekuensi yang paling banyak berada di kategori tinggi dengan persentase $61,9 \%$.

Tabel 2. Data Tingkat Harga Diri

\begin{tabular}{ccccc}
\hline No. & Kelas Interval & Frekuensi & Percent & Kategori \\
\hline 1. & $10-17,4$ & 0 & 0 & Sangat Rendah \\
2. & $17,5-22,4$ & 1 & 0,3 & Rendah \\
3. & $22,5-27,4$ & 42 & 12,2 & Sedang \\
4. & $27,5-32,4$ & 213 & 61,9 & Tinggi \\
5. & $32,5-40$ & 88 & 25,6 & Sangat Tinggi \\
& Total & $\mathbf{3 4 4}$ & $\mathbf{1 0 0}$ & \\
\hline
\end{tabular}

Mengacu pada data yang disajikan pada tabel 3, maka tingkat fear of missing out paling banyak berada di kategori sedang dengan persentase $35,2 \%$.

Tabel 3. Data Tingkat Fear of Missing Out

\begin{tabular}{ccccc}
\hline No. & Kelas Interval & Frekuensi & Percent & Kategori \\
\hline 1. & $10-17,4$ & 21 & 6,1 & Sangat Rendah \\
2. & $17,5-22,4$ & 88 & 25,6 & Rendah \\
3. & $22,5-27,4$ & 121 & 35,2 & Sedang \\
4. & $27,5-32,4$ & 87 & 25,3 & Tinggi \\
5. & $32,5-40$ & 27 & 7,8 & Sangat Tinggi \\
& Total & $\mathbf{3 4 4}$ & $\mathbf{1 0 0}$ & \\
\hline
\end{tabular}

Sebelum melakukan uji regresi diperlukan melakukan uji asumsi klasik. Uji asumsi klasik yang dilakukan yaitu uji normalitas, uji heterokedastisitas dan uji multikolinearitas. Hasil uji normalitas terdapat pada gambar 1 yaitu menampilkan histogram menunjukan bahwa data memiliki kurva normal. Adapun hasil uji normalitas dengan menggunakan uji probability plot (gambar 2) didapatkan hasil data mendekati garis diagonalnya sehingga dapat disimpulkan bahwa data berdistribusi normal. Sedangkan hasil uji Klomogorov Smirnov didapatkan nilai residual 0,17 $>0,05$ yang berarti bahwa data berdistribusi normal.

Berdasarkan hasil uji linearitas diketahui nilai Sig.deviation from linearity sebesar 0,29 > 0,05, maka dapat disimpulkan bahwa terdapat hubungan yang linear antara harga diri, FoMO dan smartphone addiction. Menurut Ghozali (2011: 107-108) tidak terjadi gejala multikolinearitas jika nilai Tolerance $>0,100$ dan VIF $<10,00$. Pengujian ini dilakukan dengan bantuan aplikasi JASP for Windows. Hasil pengujian dengan menggunakan JASP didapatkan hasil variabel harga diri (X1) memiliki nilai tolerance $0,955>0,1$ dan nilai VIF 1,047 < 10, sedangkan variabel FoMO (X2) memiliki nilai tolerance $0,955>0,1$ dan VIF $1.047<10$. Berdasarkan hasil nilai tolerance dan VIF tersebut maka dapat disimpulkan bahwa tidak terjadi gejala multikolinearitas.

Sementara uji heterokedastisitas dihasilkan gambar 3 scatterplot di bawah, tidak ada pola yang jelas pada gambar, serta titik-titik menyebar di atas dan di bawah angka 0 pada sumbu Y. sehingga dapat disimpulkan bahwa tidak ada gejala heterokedastisitas. 


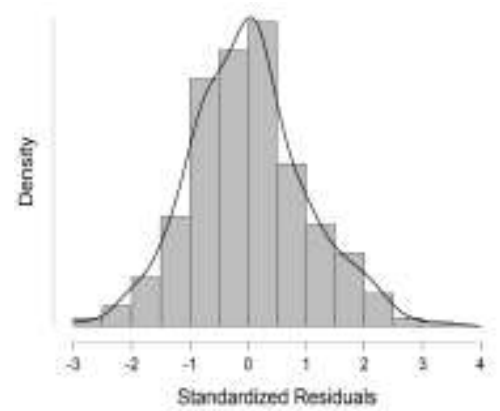

Gambar 1. Histogram

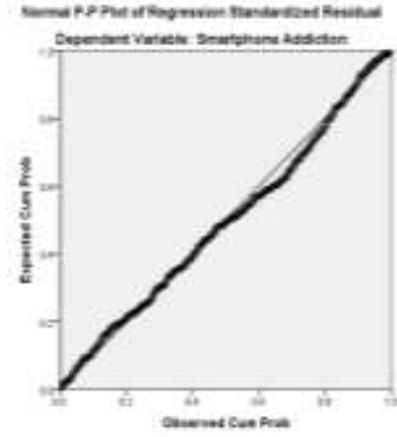

Gambar 2. Probability Plot

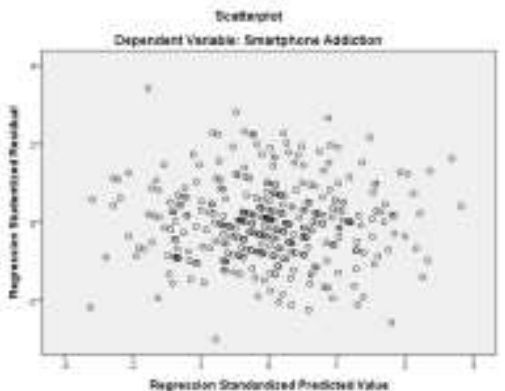

Gambar 3.Scatterplot

\section{Hubungan antara Harga Diri dan FoMO pada Mahasiswa Universitas Negeri Semarang}

Hasil uji hipotesis hubungan antara harga diri dan FoMO dapat dilihat pada hasil uji korelasi pada tabel 4.2 bahwa korelasi antara variabel harga diri dan FoMO didapat nilai koefisien sebesar 0,213. Berdasarkan hasil tersebut dapat disimpulkan bahwa variabel harga diri dan FoMO memiliki hubungan yang negative dan memiliki hubungan yang rendah karena berda di rentang 0,20-0,399 pada tabel 3.18. Selain itu apabila nilai Signifikansi $<0,05$ maka terjadi hubungan yang signifikan, sedangkan jika signifikansi $>0,05$ maka tidak ada hubungan yang signifikan. Hasil yang diperoleh pada tabel 4.2 di dapat 0,000 artinya ada hubungan yang signifikan antara harga diri dengan FoMO.

Tabel 4. Hasil Korelasi Pearson

\begin{tabular}{lcc}
\hline & $\begin{array}{c}\text { Pearson } \\
\text { correlation }\end{array}$ & Signifikansi \\
\hline Harga diri dengan FoMO & $-0,213$ & 0,000 \\
\hline
\end{tabular}

\section{Hubungan antara Harga Diri dan Smartphone Addiction pada Mahasiswa Universitas} Negeri Semarang

Berdasarkan hasil pengujian hipotesis yang telah dilakukan, diperoleh hasil bahwa ada hubungan yang negatif dan signifikan antara harga diri dengan smartphone addiction pada mahasiswa Universitas Negeri Semarang. Dibuktikan pada tabel 4.3 dari hasil Rhitung 0,225 dan memiliki koefisien korelasi dalam kategori rendah. Kemudian nilai signifikansi (p) pada harga diri dengan smartphone addiction pada uji t yaitu $\mathrm{p}=0,000=0 \%<5 \%$ yang berarti Ho ditolak dan Ha diterima. Sebagaimana diperoleh hasil uji determinan (R2) sebesar 0,065. Jadi terdapat sumbangan pengaruh dari harga diri dengan smartphone addiction sebesar 6.5\%. Sedangkan sisanya dipengaruhi oleh faktor lain yang tidak diteliti.

\section{Hubungan antara FoMO dan Smartphone Addiction pada Mahasiswa Universitas Negeri Semarang}

Berdasarkan hasil pengujian hipotesis yang telah dilakukan, diperoleh hasil bahwa ada hubungan yang negatif dan signifikan antara fear of missing out dengan smartphone addiction pada mahasiswa Universitas Negeri Semarang. Dibuktikan pada tabel 4.3 dari hasil Rhitung 0,371 dan memiliki koefisien korelasi dalam kategori rendah. Kemudian nilai signifikansi ( $\mathrm{p}$ ) pada fear of missing out dengan smartphone addiction pada uji t yaitu $\mathrm{p}=0,000=0 \%<5 \%$ yang berarti Ho ditolak dan Ha diterima. Sebagaimana diperoleh hasil uji determinan (R2) sebesar 0,138. Jadi terdapat 
sumbangan pengaruh dari fear of missing out dengan smartphone addiction sebesar 13,8\%. Sedangkan sisanya dipengaruhi oleh faktor lain yang tidak diteliti.

\section{Hubungan antara Harga Diri dan FoMO dengan Smartphone Addiction pada Mahasiswa Universitas Negeri Semarang}

Hasil uji hipotesis hubungan harga diri dan FoMO dengan smartphone addiction pada mahasiswa Universitas Negeri Semarang dapat dilihat melalui hasil uji simultan (uji F) variabel X1 dan X2 terhadap Y dapat dilihat hasil uji simultan (R2) yaitu mengukur seberapa jauh kemampuan model dalam menerangkan variabel dependen. Hasil yang diperoleh menunjukkan bahwa hasil $\mathrm{R}_{\text {hitung }}=0,413$ dan koefisien korelasi termasuk dalam kategori sedang. Kemujian uji $\mathrm{F}$ diperoleh $\mathrm{F}=$ $34,967>1,960$ dengan tingkat signifikansi $0,000=0 \%<5 \%$ yang berarti Ho ditolak dan Ha diterima. Dengan demikian dikatakan ada hubungan yang positif dan signifikan antara harga diri dan FoMO dengan smartphone addiction. Sebagaimana pada tabel 4.3 diperoleh hasil uji determinan (R2) sebesar 0,17. Jadi terdapat sumbangan pengaruh dari harga diri dan FoMO dengan smartphone addiction sebesar 17\%. Sedangkan sisanya sebesar $83 \%$ dipengaruhi oleh faktor lain yang tidak diteliti.

Tabel 5. Hasil Uji Regresi Terhadap Smartphone Addiction

\begin{tabular}{cccccc}
\hline No. & Variabel & $\mathbf{R}$ & $\mathbf{R}^{2}$ & $\mathbf{F}$ & Sig. \\
\hline 1. & Harga diri & 0,225 & 0,065 & 23,745 & 0.000 \\
2. & Fear of Missing Out & 0,371 & 0,138 & 54,663 & 0.000 \\
3. & $\begin{array}{c}\text { Harga diri dan Fear of } \\
\text { Missing Out }\end{array}$ & 0,413 & 0,17 & 34,967 & 0.000 \\
\hline
\end{tabular}

\section{Diskusi}

Berdasarkan tujuan penelitian pada sub-bab ini akan diuraikan pembahasan hasil penelitian yang meliputi, deskripsi data harga diri, fear of missing out dan smartphone addiction dan hubungan antar tiga varabel tersebut pada mahasiswa Universitas Negeri Semarang. Hasil penelitian ini diperoleh dari analisis deskriptif dan analisis regresi terhadap skala harga diri, skala fear of missing out dan skala smartphone addiction yang diberikan kepada 344 responden. Berikut uraian dan diskusi hasil penelitian:

\section{Hubungan Harga Diri dengan Smartphone Addiction pada Mahasiswa Universitas Negeri Semarang}

Hasil perhitungan hipotesis menunjukan bahwa ada hubungan yang negatif dan signifikan antara harga diri dan smartphone addiction pada mahasiswa Universitas Negeri Semarang. Hal ini memiliki arti bahwa semakin tinggi harga diri maka smartphone addiction akan semakin rendah dan berlaku sebaliknya, apabila mahasiswa memiliki harga diri yang rendah maka akan smartphone addiction akan semakin tinggi. Berdasarkan penelitian yang dilakukan oleh Bianchi dan Philips (2005), individu yang memiliki harga diri yang rendah akan lebih memilih berkomunikasi secara tidak langsung melalui media sosial sementara individu dengan harga diri yang tinggi lebih menyukai komunikasi secara face to face (komunikasi langsung). Individu yang memiliki self-esteem rendah lebih memilih untuk menggunakan smartphone karena menilai smartphone merupakan 
tempat untuk bisa mengekspresikan diri. Chen et al (2019) di dalam penelitiannya menjelaskan bahwa individu menggunakan smartphone untuk memenuhi kebutuhan mereka untuk dihargai melalui media yang tidak tersedia di dunia fisik, yang pada akhirnya menciptakan ketergantungan pada smartphone (smartphone addiction). Untuk itu mahasiswa perlu belajar menerima diri secara utuh, membuat relasi yang positif dengan lingkungan sekitar dan meningkatkan kompetensi diri agar dalam tugas perkembangannya dalam membentuk self esteem bisa terpenuhi sehingga dapat mengurangi resiko smartphone addiction. Sementara itu individu yang memiliki harga diri yang tinggi lebih menikmati lingkungan pergaulan sosialnya dan menggunakan smartphone sesuai dengan kebutuhan (Dlodlo, 2014). Hal ini sesuai dengan penelitian yang dilakukan oleh Zhang et al (2015) bahwa remaja yang memiliki harga diri yang tinggi bisa mencegah kecanduan smartphone. Berdasarkan penjelasan tersebut dapat disimpulkan bahwa harga diri memiliki hubungan yang negatif dengan smartphone addiction dan menjadi faktor prediktor smartphone sebesar 6,5\%.

\section{Hubungan Fear of Missing Out dengan Smartphone Addiction pada Mahasiswa Universitas Negeri Semarang}

Hasil perhitungan hipotesis menunjukan ada hubungan yang positif dan signifikan antara fear of missing out (FoMO) dan smartphone addiction pada mahasiswa Universitas Negeri Semarang. Hal ini menunjukan bahwa semakin tinggi tingkat FoMO pada mahasiswa, maka tingkat smartphone addiction akan semakin tinggi. Namun, apabila mahasiswa memiliki tingkat FoMO yang rendah maka tingkat smatphone juga akan semakin rendah. Hasil penelitian ini sesuai dengan hasil penelitian Przybylski, Murayama, DeHaan dan Gladwell (2013) yang menyatakan bahwa individu yang memiliki tingkat FoMO yang tinggi maka akan cenderung menggunakan smartphone mereka saat mengendarai atau duduk di kelas. Berdasarkan penelitian (Akbay, 2019) menunjukan bahwa penyebab kecanduan media sosial di kalangan remaja adalah kecanduan smartphone yang mana faktor yang menjadi prediksi penyebab kecanduan smartphone adalah rasa takut akan ketinggalan (fear of missing out). Kemudian berdasarkan hasil uji regresi dihasilkan nilai R2 sebesar 0,138 yang mana dapat diartikan bahwa variabel FoMO memberikan sumbangan sebesar 13,8\% terhadap smartphone addiction dan 86,2\% ditentukan oleh faktor lain. Hal ini juga diperkuat dari penelitian beberapa penelitian lain juga menunjukan bahwa FoMO juga merupakan variabel yang paling terkait dengan penggunaan smartphone yang bermasalah (Alt, 2015; Clayton, Leshner \& Almond, 2015;Elhai dkk., 2016; Przybylski et al., 2013). Berdasarkan temuan tersebut mahasiswa supaya memenuhi kebutuhan dirinya akan self dan relatedness karena kedua kebutuhan psikologis tersebut merupakan faktor yang menyebabkan terjadinya FoMO yang mana, FoMO ini bisa meningkatkan resiko kecanduan smartphone. Berdasarkan dari beberapa penelitian tersebut menunjukan bahwa FoMO memiliki hubungan dengan smartphone addiction dan menjadi faktor prediktor smartphone addiction sebesar 13,8\%.

\section{Hubungan Harga Diri dan Fear of Missing Out dengan Smartphone Addiction pada Mahasiswa Universitas Negeri Semarang}

Smartphone addiction disebabkan oleh beberapa faktor yang mana beberapa diantaranya yaitu faktor social gratification yang diungkapkan oleh Walsh et al (2007) yang menerangkan bahwa seorang individu, khususnya mahasiswa penggunaan smartphone karena menjaga kontak dengan orang lain dan kebutuhan untuk terhubung dengan orang lain. Hal ini seperti yang diungkapkan oleh Hato (2013) dalam tesisnya mengatakan bahwa remaja selalu ingin berkomunikasi dengan kelompok atau teman sebayanya, jika mereka tidak bertemu secara langsung mereka 
menggunakan smartphone untuk berkomunikasi dengan orang-orang yang menurut mereka penting secara terus menerus. Tujuannya agar komunikasi mereka tidak terputus dan mendapatkan akses cepat menuju informasi terkini melalui fitur yang ada pada smartphone dan layanan internet. Media sosial memainkan peran penting dalam menjaga mahasiswa tetap terhubung dengan keluarga dan teman agar mendapat dukungan sosial (Gemmill \& Peterson, 2006). Namun, menurut Kurcaburun (2016) orang yang ingin mendapat banyak dukungan dari teman atau lingkungan sekitarnya merupakan individu yang memiliki harga diri yang rendah. Orang yang memiliki tingkat harga diri yang rendah akan mengalami smartphone addiction Sing et al (2014). Penelitian Davis (2001) meneliti bahwa harga diri yang rendah merupakan aspek kritis dari kognisi maladaptif. Individu yang rendah mempercayai bahwa mereka lebih dijunjung tinggi hanya dalam interaksi online dan akibatnya, individu yang memiliki harga diri rendah menggunakan smartphone untuk mendapatkan persetujuan dan pengakuan dari orang lain. Kemudian Chen et al (2019) di dalam penelitiannya menjelaskan bahwa individu menggunakan smartphone untuk memenuhi kebutuhan mereka untuk dihargai melalui media yang tidak tersedia di dunia fisik, yang pada akhirnya menciptakan ketergantungan pada smartphone (smartphone addiction). Padahal saat ini terhubung dengan orang lain dengan menggunakan smartphone sepanjang hari dan tidak kehilangan koneksi apapun merupakan hal yang dianggap penting bagi banyak orang (Aoki \& Downes, 2003). Ketika individu tidak mendapatkan informasi yang diketahui teman atau kelompoknya, terkadang ia mulai merasa takut atau cemas. Fenomena cemas tertinggal informasi itu dinamakan fear of missing out (FoMO). FoMO merupakan kekhawatiran yang timbul karena seseorang tidak berada dalam situasi atau aktivitas yang sama dengan orang lain atau kelompok (Przybylski, Murayama, DeHaan, dan Gladwell, 2013). FoMO juga terbukti menjadi prediktor beberapa perilaku yang merugikan, yaitu perilaku mengecek smartphone secara kompulsif (Collins, 2013; Hato, 2013) dan ketergantungan pada smartphone (Collins, 2013). Hasil perhitungan hipotesis menunjukan bahwa harga diri dan FoMO secara simultan memiliki hubungan yang positif dan signifikan dengan smartphone addiction. Kedua variabel tersebut juga memiliki pengaruh sebesar 17\% terhadap dan hal lainnya merupakan faktor lain yang tidak diteliti.

\section{Simpulan}

Berdasarkan hasil penelitian yang telah dilaksanakan, berikut simpulan dan saran mengenai hubungan harga diri dan fear of missing Out (FoMO) dengan smartphone addiction pada mahasiswa Universitas Negeri Semarang (1) Ada hubungan yang signifikan antara harga diri dengan smartphone addiction pada mahasiswa Universitas Negeri Semarang. Semakin tinggi tingkat harga diri maka smartphone addiction akan semakin rendah dan sebaliknya, apabila memiliki harga diri rendah maka smartphone addiction akan semakin tinggi (2) Ada hubungan yang signifikan antara FoMO dengan smartphone addiction pada mahasiswa Universitas Negeri Semarang. Semakin tinggi tingkat FoMO maka smartphone addiction akan semakin tinggi dan berlaku sebaliknya apabila FoMO rendah maka smartphone addicion akan semakin rendah.(3) Harga diri dan smartphone addiction secara bersama-sama memiliki hubungan yang signifikan dan saling mempengaruhi sebesar 17\% dan 83\% lainnya ditentukan oleh faktor lain yang tidak diteliti. Dari hasil penelitian, disarankan hasil penelitian ini bagi penelitian selanjutnya diharapkan dapat meneliti faktor lain yang tidak diteliti mengenai harga diri, fear of missing out dan smatphone addiction serta meneliti layanan yang sesuai untuk menangani smartphone addiction. Kemudian bagi guru bimbingan dan 
konseling, dapat memberikan layanan bimbingan dan konseling yang sesuai dengan kebutuhan para siswa seperti layanan klasikal, layanan kelompok dengan menggunakan teknik yang yang bisa meningkatkan harga diri dan mengurangi fear of missing out dan smartphone addiction.

\section{Referensi}

Agusta, D. (2016). Faktor-faktor Resiko Kecanduan Menggunakan Smartphone pada siswa di SMK Negeri 1 Kalasan Yogyakarta. E-Journal Bimbingan dan Konseling, 86-96.

Alfaiz, A., \& Yandri, H. (2015). Self concept and self efficacy as a ground points in a social activities (an analysis of psychology perspective: a social cognitive theory). Jurnal Pelangi, 7(2).

Andrew K. Przybylski a, 爪. K. (2013). Motivational, emotional, and behavioral correlates of fear of missing out. Elsevier Journal.

Chiu, S. (2014). The Relationship Between Life Stress annd Smartphone Addiction On Taiwanes University Student: A Meditation Model of Learning Self Efficacy and Social efficacy . Computer and Human Behaviour, 49-57.

Choi, H. J. (2015). A Study on the Relationship between Self-Esteem, Social Support, Smartphone Dependency, Internet Game Dependency of College Students. Journal of EastWest Nursing Research, 21(1): 78-84.

Coopersmith, Stanley . 1967. The Antecendent Of Self Esteem ,(San Fransisco : W.H Freeman and Company), 75 .

Dwi, Y. R. (2017). Hubungan Antara Self-Esteem dengan FOMO pada Mahasiswa Univeritas Mercu Buana Yogyakarta. International Journal of Applied Guidance and Counseling.

Freeman, C. (2008). Internet Gaming Addiction. The Journal for Nurse Practitioners, 42-47.

Griffiths, M. T. (2003). The Exercise Addiction Inventoty: A New Brief Screening Tool. . Addiction Research Teori, Vol. 12(5).

Indrawan. 2015. Orang Indonesia makin kecanduan smartphone, ini data terbaru. Batamnews diakses pada Januari 2020.

JW'T. (2012). Fear of Missing Out (FoMO). Retrieved from JW'T Intelligence: http://www.jwtintelligence.com/wpcontent/uploads/2012/03/F_JWT_FO

Kwon, M. e. (2013). The smartphone addiction scale: development and validation of a short version for adolescents. . PLOS ONE, 8(12).

Kwon, M. K. (2013). Development and validation of a smartphone addiction scale . PLoS ONE, $8(2)$.

Kyoung, M. Y. (2016). The Effect of Self-esteem and Depresion on Smartphone Addiction among University Students. Journal of the Korea Convergence Society Vol. 7. No. 1, pp. 113-123.

Lepp, A. B. (2015). The relationship between cell phone use and academic performance in a sample of US college student. Sage Journal. 
Leung, L. (2017). Lingking Psichological Attributes to Addiction and Improper Use of the Mobile Phone Among Adolecent in Hongkong. Retrieved from http://www.com.cuhk.edu.hk/ccpos/en/pdf/mp6.pdf

Morrison, T. L., Thomas, M. D., \& Weaver, S. J. (1973). Self-esteem and self-estimates of academic performance. Journal of Consulting and Clinical Psychology, 41(3), 412415. https://doi.org/10.1037/h0035337

Mulyana, S., \& Afriani, A. (2017). Hubungan Antara Self-Esteem dengan Smartphone Addiction pada Remaja SMA di Kota Banda Aceh. Journal Psikogenesis, 5(2), 102. https://doi.org/10.24854/jps.v5i2.499

Poushter, Jacob. 2016. Smartphone Ownership and Internet Usage Continues to Climb in Emerging Economies But advanced economies still have higher rates of technology use FEBRUARY 22, 2016. https://www.pewresearch.org/global/2016/02/22/smartphone-ownershipand-internet-usage-continues-to-climb-in-emerging-economies /

Region. (2013). Ericsson Mobility Report On The Pulse of The Networked Society. Sweden: Ericsson Mobility.

Santrock, John W. (2011). Perkembangan Anak Edisi 7 Jilid 2. (Terjemahan: Sarah Genis B) Jakarta: Erlangga.

Satrio, K. (2019). Hubungan antara Self-esteem dengan Fear of Missing Out pada Mahasiswa Tahun Pertama Universitas Diponegoro. Jurnal Empati.

Smith, Aaron. U.S. Smartphone Use in 2015 Aaron Smith. 1 April 2015. https://www.pewresearch.org/internet/2015/04/01/us-smartphone-use-in-2015/ diakses pada Januari 2020.

Surakarta, S. M. A. N., Simangunsong, S., \& Sawitri, D. R. (2018). Hubungan Stres Dan Kecanduan Smartphone Pada Siswa Kelas X Sma Negeri 5 Surakarta. Empati, 6(4), 52-66.

Wolniewicz, C. A. (2019). Boredom proneness and fear of missing out mediate relations between depression and anxiety with problematic smartphone use. Wiley Empirical Article, 1-10. doi:DOI: $10.1002 /$ hbe2.159

Yuwanto, L. (2010). Mobile Phone Addict. Surabaya: Putra Media Nusantara.

Zarkasih, P. H. (2017). Memahami Ciri dan Tugas Perkembangan Masa Remaja. Aplikasia : Jurnal Aplikasi Ilmu-ilmu Agama, 25-32. 